\title{
Use of cloud point extraction for removal of nanosized copper oxide from wastewater
}

\author{
LIU JingFu*, SUN Jia \& JIANG GuiBin \\ State Key Laboratory of Environmental Chemistry and Ecotoxicology, Research Center for Eco-Environmental Sciences, Chinese Academy of \\ Sciences, Beijing 100085, China
}

Received April 3, 2009; accepted August 20, 2009

\begin{abstract}
Triton X-114 based cloud point extraction has been demonstrated to be an advantageous approach for the recovery of nanosized copper oxide (NCO) from water. The removal of NCO was influenced by the concentrations of TX-114 and salt, incubation temperature and time, as well as solution $\mathrm{pH}$. With the addition of $0.3 \%(\mathrm{w} / \mathrm{v})$ Triton $\mathrm{X}-114$, over $88 \%$ of the spiked NCO was removed from wastewater after incubation at $35^{\circ} \mathrm{C}$ for $2 \mathrm{~h}$ and centrifugation, whereas over $85 \%$ of NCO was recovered after incubation at $28^{\circ} \mathrm{C}$ for $20 \mathrm{~h}$ by gravity phase separation, which is economical and energy-saving. This study suggests that the cloud point extraction technique has great potential in removal of nanomaterials from wastewater.
\end{abstract}

cloud point extraction, copper oxide, nanomaterial, Triton X-114, wastewater

Citation: Liu J F, Sun J, Jiang G B. Use of cloud point extraction for removal of nanosized copper oxide from wastewater. Chinese Sci Bull, 2010, 55: 346-349, doi: 10.1007/s11434-009-0695-0

Nanosized $(<200 \mathrm{~nm})$ pollutants are widely present in the aqueous environment. They are transferred or enriched in the wastewater from conventional air pollution control devices such as scrubbers [1], and some traditional industrial sludges are actually nanowastes with adsorbed heavy metals or organic pollutants [2]. For example, nanoparticles $(68-120 \mathrm{~nm}$ ) have been found in CMP (chemical mechanical planarization) wastewater in the semiconductor manufacturing industries [3], and Chinese chlor-alkali and chlorate plants generate over 800 kilotons of $\mathrm{Mg}(\mathrm{OH})_{2}$-containing nanowastes per year [2]. With the development of nanotechnology and the wide application of nanomaterials, engineered nanomaterials are also inevitably released into the aqueous environment. Recently the safety of engineered nanomaterials is increasingly concerned, as studies suggested that the toxicity of nanomaterials is not only from their own intrinsic toxicity, but also from their effects on the generation, transport and exposure of toxic substances $[4,5]$.

*Corresponding author (email: jfliu@rcees.ac.cn)
Therefore, we have to address the problem of removal of nanowaste with potential toxicity.

A few procedures have been proposed for the recovery of nanomaterials from aqueous phase. $\mathrm{C}_{60}$ fullerene was extracted by liquid-liquid extraction with toluene or by solid-phase extraction with octadecylsilyl [6,7]. Ag nanoparticles were recovered with anion exchange resin beads [8], whereas $\mathrm{Au}$ nanoparticles [9], CdTe quantum dots [10], and nanosized copper [1] were extracted with ionic liquids separately. These procedures were conducted on the basis of various mechanisms, thus a general, effective, economic, and mature method that is applicable to various nanomaterials is urgently needed. Recently, our group has discovered that Triton X-114 based cloud point extraction (CPE) provides a general, simple, and cost-effective route for reversible concentration/separation and dispersion of various nanomaterials in aqueous phase [11].

The objective of this study is to evaluate the applicability of CPE for the recovery of nanomaterials in wastewater by using nanosized copper oxide (NCO) as a model. NCO is reported to widely exist in semiconductor industrial waste water with a considerable concentration [1]. 


\section{Experimental}

\subsection{Materials}

Triton X-114 (TX-114) was purchased from Acros Organics (Geel, Belgium). All the other chemicals were analyticalreagent grade or above and were obtained from Sinopharm Chemical Reagent Beijing (Beijing, China). Ultra-purified water (EASY-pure LF, Barnstead International, Dubuque, IA, USA) was used throughout the experiments.

\subsection{Synthesis of NCO}

The aqueous solution of NCO was prepared by dehydration from copper hydroxide in ethanol phase at refluxing condition which was modified according to the literature [12]. Briefly, $20 \mathrm{~mL}$ of $0.04 \mathrm{~mol} / \mathrm{L} \mathrm{Cu}\left(\mathrm{NO}_{3}\right)_{2}$ ethanol solution and $40 \mathrm{~mL}$ of $0.04 \mathrm{~mol} / \mathrm{L} \mathrm{NaOH}$ ethanol solution were added to $50 \mathrm{~mL}$ ethanol held in a $250 \mathrm{~mL}$ flask. The solution color changed to light green immediately when copper hydroxide colloid was formed. The solution color gradually changed from light green to dark brown after heating to boil and reflux for $1 \mathrm{~h}$, indicating the dehydration of copper hydroxide and the formation of copper oxide accordingly. After further heating for $1 \mathrm{~h}$, the ethanol in the solution was evaporated through a rotatory evaporator, and $\mathrm{NCO}$ was obtained and dissolved in water. After ultrasonic treatment with an Ultrasonic Cleaner (Crest Model 275HT, $38.5 \mathrm{kHz}$, USA) for $1 \mathrm{~h}$, the NCO dispersed well in the aqueous solution which was clear brown and ready for use.

\subsection{Characterization of NCO}

TEM was carried out with H-7500 (Hitachi, Japan) at $80 \mathrm{kV}$ with samples prepared by loading aliquots of the aqueous samples onto carbon-coated grid sample holders and dried at room temperature. The size distribution of the nanoparticles was estimated using Image-Pro plus software and Gaussian fitting. At least 300 particles were counted from the pictures.

The Zeta potential of NCO particles was measured at various $\mathrm{pH}$ with a Malvern Zetasizer 2000 (Malvern Instruments, UK).

\subsection{Cloud point extraction of NCO in aqueous system}

$0.3 \%(\mathrm{w} / \mathrm{v})$ of $\mathrm{TX}-114$ and $0.1 \%(\mathrm{w} / \mathrm{v})$ of $\mathrm{NaCl}$ were added to dilute NCO aqueous solution $(\sim 2 \mathrm{mg} / \mathrm{L} \mathrm{Cu})$ and the solution was heated to a temperature above the cloud point temperature $\left(\sim 23^{\circ} \mathrm{C}\right)$. Apparent phase separation occurred with the solution becoming muddy and the formation of surfactant-rich phase on the bottom. After the solution was centrifuged at $2000 \mathrm{r} / \mathrm{min}$ for $6 \mathrm{~min}$, NCO was concentrated from $10 \mathrm{~mL}$ of aqueous system into about $0.1 \mathrm{~mL}$ surfac- tant-rich phase with relatively high viscosity which appeared light yellow, while the upper aqueous phase became transparent and colorless.

\subsection{Determination of extraction efficiency}

The extraction efficiency of NCO was determined by quantification of $\mathrm{Cu}$ content in both the upper aqueous phase and the lower surfactant-rich phase after phase separation with centrifugation. The original $\mathrm{Cu}$ content in the copper oxide solution before extraction was also determined for confirmation. The $\mathrm{Cu}$ contents in these sample solutions were determined with ICP-MS (Agilent 7500ce, USA) after complete dissolution of $\mathrm{NCO}$ with $5 \%(\mathrm{v} / \mathrm{v}) \mathrm{HNO}_{3}$.

\section{Results and discussion}

\subsection{Characterization of NCO}

TEM image of the as-prepared NCO shows a typical diameter of $60 \mathrm{~nm}$, and the diameter distribution was similar to Gaussion distribution $(62.0 \pm 15.5 \mathrm{~nm})$ as shown in Figure 1. Zeta potential determination indicates that the zero point charge $\mathrm{pH}\left(\mathrm{pH}_{\mathrm{PZC}}\right)$ of the as-prepared $\mathrm{NCO}$ is $\sim 6.0$ as shown in Figure 1(c), indicating that the surface of NCO was negatively charged at $\mathrm{pH}>6.0$.

\subsection{Parameters influencing cloud point extraction effi- ciency}

Effect of TX-114 concentration on extraction efficiency of $\mathrm{NCO}$ was studied in the range of $0.06 \%-0.72 \%$. Results shown in Figure 2 reveal that the concentration of TX-114 has no significant influence on extraction efficiency as long as it is higher than its critical micelle concentration $(\sim 0.02 \%$, $\mathrm{w} / \mathrm{v})$ [13]. Without the addition of TX-114, however, phase separation of NCO was not observed by long-term gravity settling ( $7 \mathrm{~d}$ ) or centrifugation at $2000 \mathrm{r} / \mathrm{min}$ for $30 \mathrm{~min}$.

The effect of salinity on extraction efficiency of $\mathrm{NCO}$ was studied with the addition of $0-1.0 \%(\mathrm{w} / \mathrm{v}) \mathrm{NaCl}$. As shown in Figure 3, relatively high extraction efficiency was obtained at around $0.05 \% \mathrm{NaCl}$. This is because the presence of $\mathrm{NaCl}$ reduced the Coulomb repulsion among the negatively charged NCOs in TX-114 micelles and thus enhanced the phase separation. The reason for the significant reduction of extraction at $\geqslant 0.5 \% \mathrm{NaCl}$ is unclear yet.

The extraction efficiency of NCO strongly depends on the solution $\mathrm{pH}$ which determines the surface charge of the metal oxide nanoparticles. As the as-prepared NCO has a $\mathrm{pH}_{\mathrm{PZC}}$ of about 6.0 (Figure 1(c)), it was expected that a constant extraction efficiency should be obtained in the entire studied range of $\mathrm{pH} 7-12$. However, experimental results show that the extraction efficiency decreased with the decrease of $\mathrm{pH}$ in the range of $\mathrm{pH} \mathrm{7-10,} \mathrm{and} \mathrm{the} \mathrm{highest} \mathrm{ex-}$ 

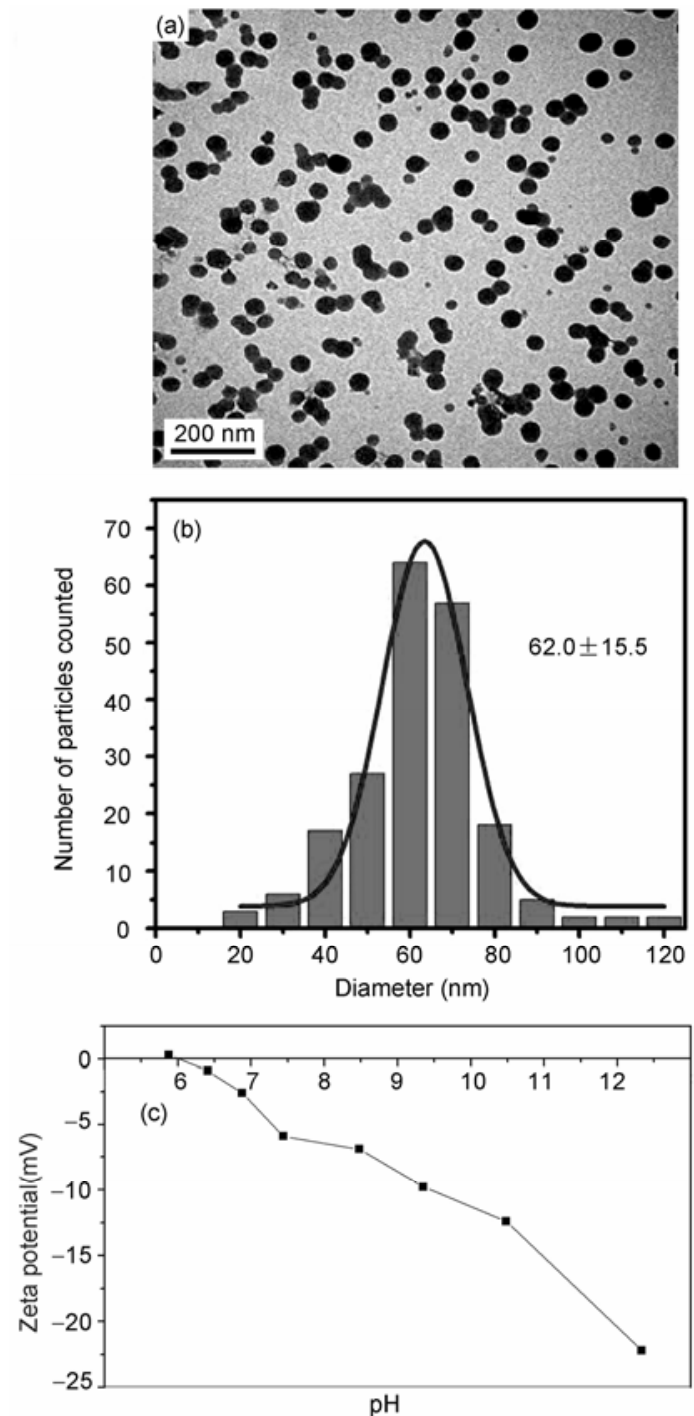

Figure 1 TEM image (a), diameter distribution (b) and Zeta potential (c) of the as-prepared copper oxide nanoparticles.

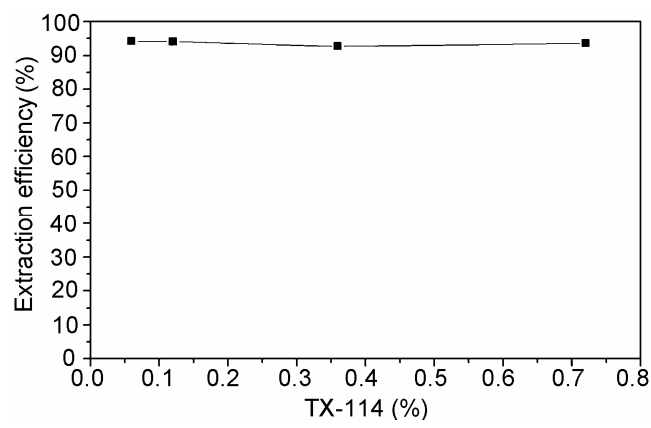

Figure 2 Effect of TX-114 concentration on extraction efficiency of nanosized copper oxide. Extraction was conducted with a constant temperature of $45^{\circ} \mathrm{C}, \mathrm{pH} 10.3,0.1 \%(\mathrm{w} / \mathrm{v}) \mathrm{NaCl}$, and incubation time of $2 \mathrm{~h}$.

traction efficiency was obtained at $\mathrm{pH}$ 10-12 (Figure 4). The slightly lower extraction efficiency at $\mathrm{pH} 7-10$ might be attributed to the part dissolution of NCO. The extraction efficiency at $\mathrm{pH}<7$ was not tested in this study due to the

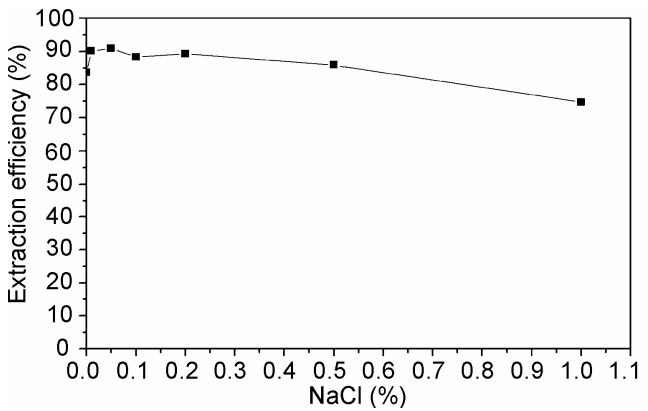

Figure 3 Effect of $\mathrm{NaCl}$ concentration on extraction efficiency of nanosized copper oxide. Extraction system was conducted at a temperature of $45^{\circ} \mathrm{C}, \mathrm{pH} 9.36, \mathrm{TX}-114$ concentration of $0.3 \%(\mathrm{w} / \mathrm{v})$, and incubation time of $2 \mathrm{~h}$.

marked dissolution of $\mathrm{NCO}$ to form $\mathrm{Cu}^{2+}$.

The effects of incubation temperature and time on the extraction efficiency of $\mathrm{NCO}$ were tested as the temperature and duration of the cloud point extraction usually have some effects. The incubation temperature was optimized in the range of $35-65^{\circ} \mathrm{C}$. No significant variation of extraction efficiency was observed as TX-114 has a lower critical solution temperature of $\sim 23^{\circ} \mathrm{C}[13,14]$, and clouding and phase separation occurred at room temperature. Figure 5 shows the effect of incubation time on extraction efficiency of NCO. When the centrifugation step was conducted, it seems that at temperatures above the cloud point, the extraction equilibration was reached in $20 \mathrm{~min}$, which agreed well with the results in most literature in which equilibration time in the range of 20-30 min was reported [14]. From an economic and energy saving point of view, conducting the extraction procedure at lower temperatures and without centrifugation is of great interest. Therefore, further experiments were performed by using gravity settling for phase separation at $38^{\circ} \mathrm{C}$ and $28^{\circ} \mathrm{C}$, separately. Results shown in Figure 5 indicate that by using gravity settling for phase separation, the extraction efficiency increased with incubation time, and the lower the incubation temperature, the longer time was needed for reaching equilibration, which agreed with the result in the literature [15]. It is noteworthy

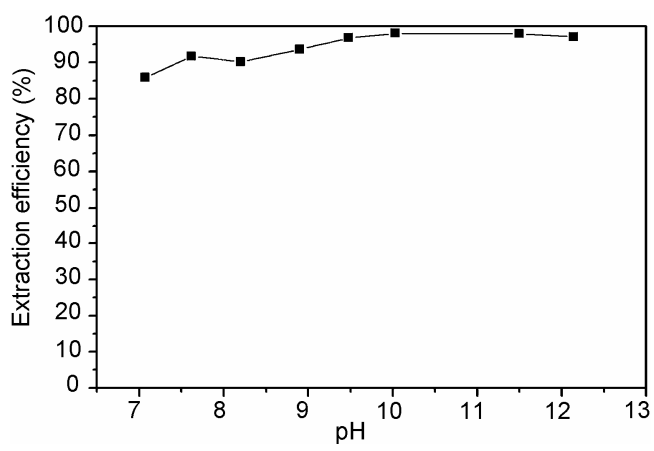

Figure 4 Effect of $\mathrm{pH}$ on extraction efficiency of nanosized copper oxide. The extraction was conducted at a temperature of $45^{\circ} \mathrm{C}, 0.1 \%(\mathrm{w} / \mathrm{v}) \mathrm{NaCl}$, $0.3 \%(\mathrm{w} / \mathrm{v}) \mathrm{TX}-114$, and incubation time of $2 \mathrm{~h}$. 


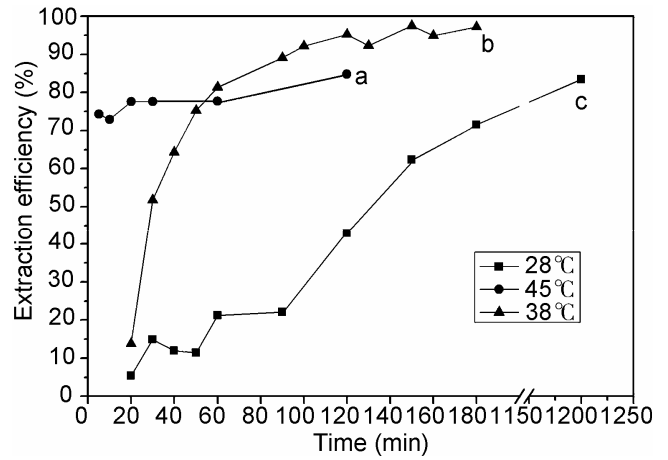

Figure 5 Effect of incubation time on extraction efficiency of nanosized copper oxide at various temperature with (a) and without (b, c) centrifugation.

that over $85 \%$ of $\mathrm{NCO}$ can be recovered with $20 \mathrm{~h}$ incubation at $28^{\circ} \mathrm{C}$, which is an energy-saving procedure.

\subsection{Removal of NCO in real wastewater}

To test the applicability of this proposed procedure to the removal of NCO from real wastewater, into the influent of a wastewater treatment plant was spiked with $2.28 \mathrm{mg} / \mathrm{L}$ of the as-prepared NCO and $0.3 \% \mathrm{TX}-114$, and the obtained mixture was incubated at $35^{\circ} \mathrm{C}$ for $2 \mathrm{~h}$. After phase separation with centrifugation, $88 \%$ of $\mathrm{NCO}$ was removed from wastewater into the surfactant-rich phase. Addition of $\mathrm{NaCl}$ $(0-0.2 \%)$ has no effect on the removal of NCO from wastewater, which was attributed to the fact that the wastewater contains a certain content of salt.

\section{Conclusions}

NCO was successfully extracted from aqueous solutions with TX-114 based cloud point extraction. The extraction efficiency of $\mathrm{NCO}$ is dependent on the concentration of $\mathrm{X}-114$ and salt, incubation temperature and time, as well as solution $\mathrm{pH}$. Over $88 \%$ of $\mathrm{NCO}$ was removed from wastewater at optimized conditions, whereas over $85 \%$ of $\mathrm{NCO}$ was recovered with $20 \mathrm{~h}$ incubation at $28^{\circ} \mathrm{C}$ by gravity phase separation, which is economic and energy-saving. This study suggests that the TX-114 based cloud point extraction technique has great potential in practical applications such as wastewater treatment and recycling of nanomaterials.

This work was supported by the National Natural Science foundation of China (Grant No. 20621703) and Major State Basic Research Development Program of China(Grant No.2010CB 933500).

1 Huang H L, Wang H P, Wei G T, et al. Extraction of nanosize copper pollutants with an ionic liquid. Environ Sci Technol, 2006, 40: 4761-4764

2 Liu W, Huang F, Liao Y, et al. Treatment of Cr(VI)-containing $\mathrm{Mg}(\mathrm{OH})_{2}$ nanowaste. Angew Chem Int Ed, 2008, 47: 1-5

3 Huang Y J, Wang H P, Hsiao M C, et al. Speciation of copper in micropores. Water Air Soil Pollut, 2004, 153: 187-194

4 Colvin V L. The potential environmental impact of engineered nanomaterials. Nat Biotechnol, 2003, 21: 1166-1170

5 Hu X L, Liu J F, Mayer P, et al. Impacts of some environmentally relevant parameters on the sorption of PAHs in aqueous suspensions of $\mathrm{C}_{60}$ fullerene. Environ Toxicol Chem, 2008, 27: 1868-1874

6 Isaacson C W, Usenko C Y, Tanguay R L, et al. Quantification of fullerenes by LC/ESI-MS and its application to in vivo toxicity assays. Anal Chem, 2007, 79: 9091-9097

7 Chen Z, Westerhoff P, Herckes P. Quantification of C-60 fullerene concentrations in water. Environ Toxicol Chem, 2008, 27: 1852-1859

8 Manikandan S, Majumdar G, Chowdhury D, et al. Solid-state storage of $\mathrm{Ag}$ nanoparticles in anion exchange resin beads. J Colloid Interface Sci, 2006, 295: 148-154

9 Wei G T, Yang Z S, Lee C Y, et al. Aqueous-organic phase transfer of gold nanoparticles and gold nanorods using an ionic liquid. J Am Chem Soc, 2004, 126: 5036-5037

10 Nakashima T, Kawai T. Quantum dots-ionic liquid hybrids: Efficient extraction of cationic CdTe nanocrystals into an ionic liquid. Chem Commun, 2005, 12: 1643-1645

11 Liu J F, Liu R, Yin Y G, et al. Triton X-114 based cloud point extraction: A thermoresversible approach for separation/concentration and dispersion of nanomaterials in aqueous phase. Chem Commun, 2009, 11: $1514-1516$

12 Hong Z S, Cao Y, Deng J F. A convenient alcohothermal approach for low temperature synthesis of $\mathrm{CuO}$ nanoparticles. Mater Lett, 2002, 52: 34-38

13 Quina F H, Hinze W L. Surfactant-mediated cloud point extractions: An environmentally benign alternative separation approach. Ind Eng Chem Res, 1999, 38: 4150-4168

14 Rubio S, Perez-Bendito D. Supra-molecular assemblies for extracting organic compounds. Trends Anal Chem, 2003, 22: 470-485

15 Akita S, Takeuchi H. Cloud-point extraction of organic compounds from aqueous solutions with nonionic surfactant. Sep Sci Technol, 1995, 30: 833-846 